\title{
Hydrocarbon field development forecast based on an integrated approach
}

\author{
D.A. Zavyalov ${ }^{1,2}$ \\ zda@tpu.ru \\ ${ }^{1}$ Tomsk Polytechnic University, Tomsk, Russia \\ ${ }^{2}$ Keldysh Institute of Applied Mathematics RAS, Moscow, Russia
}

\begin{abstract}
A hydrocarbon field is a large and complex system, which functioning is possible only in accordance with a project document that defines the main characteristics for the entire period of field development. Therefore, the quality of the project document largely determines the efficiency of the field system functioning. The last stage in creating a project document for the development of a field is an economic assessment. According to the experience of designing the development of hydrocarbon fields, up to 50\% of capital investments are the costs of drilling new wells of various types. Thus, the economic efficiency of field development is largely determined by the volume of drilling new wells. The article presents an integrated approach to modeling the development of hydrocarbon deposits in making a production forecast. Such an integrated approach involves performing a rapid economic assessment using Economics software which allows you to calculate the main economic indicators of field development. Thus, it reduces the total number of iterations for setting the forecast for field development strategy by an average of $25 \%$ as well as improves the economic characteristics of the whole project.
\end{abstract}

Keywords: oil and gas field, oil field managing, integrated approach, economic estimation.

\section{Introduction}

The complexity of the structure of such a system as hydrocarbon deposits, as well as the complexity of the management processes of such a system, determine the importance of strategic planning. The development of hydrocarbon deposits is carried out in accordance with the project document, which is a long-term field development strategy and states the number of drilling of new wells, volumes of hydrocarbon production, the need and volume of construction of new infrastructure facilities (such as pipelines, living and working spaces, power plants and others) and new research (seismic, exploration drilling, borehole surveys and more) volumes.

Therefore, the quality of the field development forecast is the determining function of efficiency of the functioning of such a complex system. The forecast is drawn up for the entire period of field development and must take into account the influence and interaction of all components of the hydrocarbon field system, as well as adjacent systems. However, the existing approaches to managing field development have a number of significant drawbacks: disunity of specialists, multivariance and iterativeness of designing stages, dependence of the result of each stage on the quality of previous ones.

So, to increase the efficiency of hydrocarbon field development management, an integrated approach to the process of formation of a development strategy is required.

\section{Integrated approach to modeling the development of hydrocarbon deposits}

In general, the process of project management of hydrocarbon field development is a sequence of stages presented on Fig. 1. This process involves the sequential execution of the following stages:

- processing of initial data (including data verification and formatting);

- geological modeling of the field (construction of a geological static model for assessing the structure of the field and calculating the volume of hydrocarbon reserves);
- hydrodynamic modeling (construction of a hydrodynamic model of the field based on geological model);

- development forecast (calculation of several forecast variants for field development strategy based on a hydrodynamic model);

- economic assessment of the forecast (calculation of economic indicators of forecast variants for field development strategy).

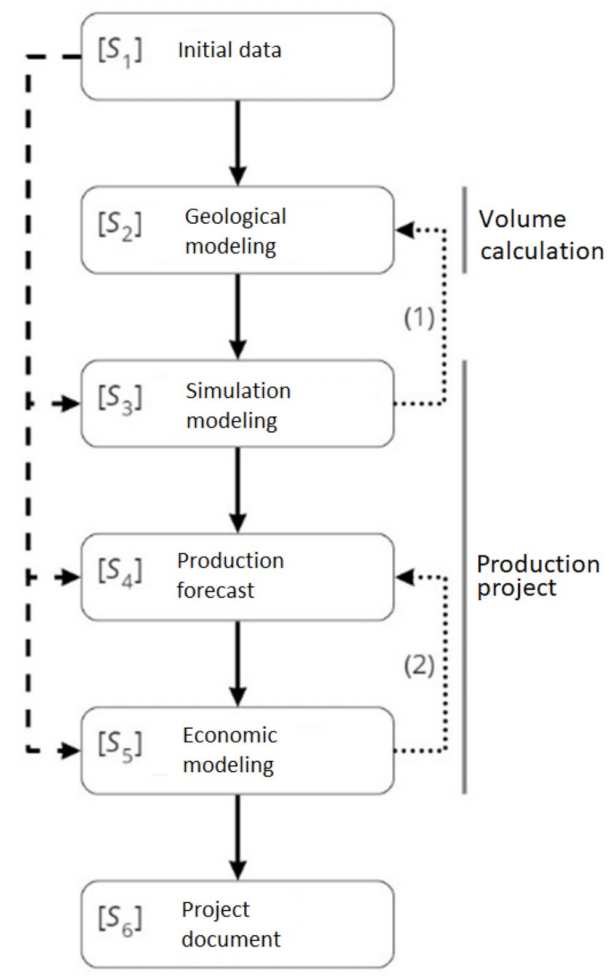

Fig. 1. Stages of the project management process for hydrocarbon field development

The result of presented sequence of stages is a project document for the development of the field.

The main types of projects are the calculation of hydrocarbon reserves (assumes the implementation of 
stages $S_{1}-S_{2}$ ) and the forecast of field development (assumes the implementation of the entire chain of stages $\left.S_{1}-S_{6}\right)$.

Stages $S_{2}, S_{4}, S_{5}$ are variable (require a lot of variants for decision making) and iterative (each variant is calculated many times till the satisfactory result is obtained), and unsatisfactory results of stages $S_{3}, S_{5}$ may require returning to the previous stages (arrows (1) and (2) on Figure 1) in order to correct some options or completely change the approach to development design.

The most time-consuming is stage $S_{4}$ - development forecast, the result of which becomes a long-term strategy for the functioning of the field. When performing this stage, iterative modeling of a number of field development forecast variants (the number of variants depends on the complexity of the structure of the field and can be several dozen) is used [1, 2].

For example, at one of the fields in the Tomsk Region there are 4 reservoirs by different in properties, for each of which 3 variants are first calculated to select the system for placing project wells, and then for the selected placement system for each reservoir 4 more variants are calculated to select the optimal operating modes for project wells. Thus, the total number of variants is 28 , while the average number of tuning iterations of one variant is 10 . The time of one iteration includes the time of calculating the model and setting its parameters and varies from several hours to a week depending on the complexity and dimension of the model, the number of phases and other parameters. All this determines the laboriousness of obtaining a field development forecast.

As experience in the implementation of hydrocarbon field development projects shows, economic profitability is largely determined by the volume of well drilling, since up to $50 \%$ of the capital investment is in drilling the production and injection wells.

Figs. 2 and 3 show the example structure of capital investments in the development of one of the real deposits in the Tomsk region [3]. In this example, the project costs for drilling new wells in 2021-2025 (during this period, the main part of the forecast wells was drilled) ranged from $30 \%$ to $80 \%$ of the amount of capital investments (Figure 2 ), while the total costs for the entire period reached $44 \%$ (Figure 3) of the total amount of capital investments to field development.

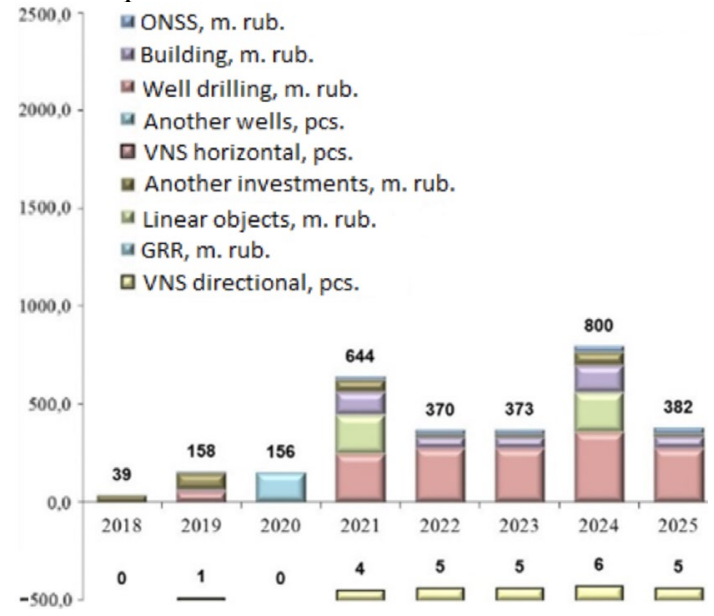

Fig. 2. An example of the structure of capital investments in the development of an oil field by years
If we talk about economic factors which the most strongly influence on the development of the field, external macroeconomic indicators should also be distinguished, however, they are difficult to predict and cannot be changed. Such indicators must be incorporated into the project to reduce uncertainties $[4,5]$.



Fig. 3. An example of the structure of total capital investments in the development of an oil field

The cost of extracting one ton of raw material is characterized by such an indicator as a ton of unit fuel. The value of this indicator at the end of the development period as production levels fall, increases (see Figure 4). Thus, the maintenance of a low-rate well becomes unprofitable. However, an incorrect determination of the location of the well drilling may lead to the fact that the low oil production rate obtained in it will not allow to recoup the cost of its drilling. Therefore, it is necessary to exclude obviously ineffective (from an economic point of view) wells from the forecast variants for the development of the field in order to increase the overall cost-effectiveness of the development variant.

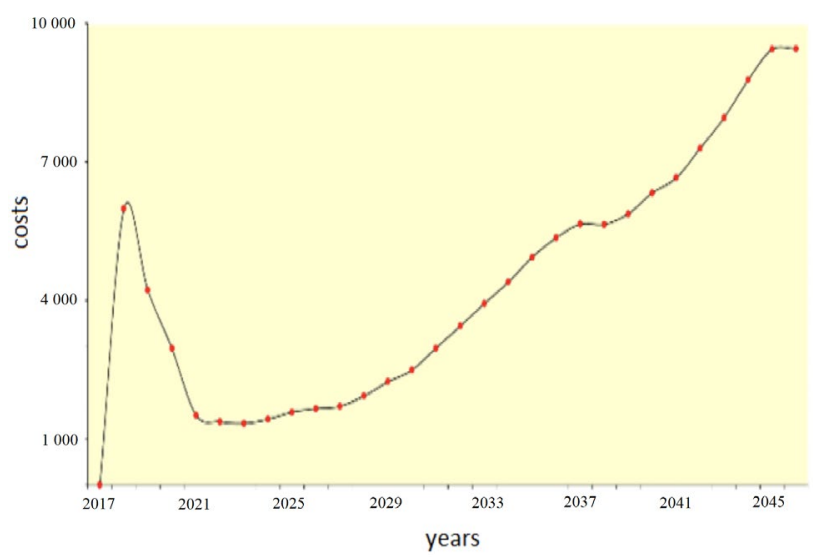

Fig. 4. An example of a graph of average costs per ton of unit fuel

To reduce the interactiveness of predictive modeling, it is necessary to consider economic parameters at the stage of formation of development variants:

- accounting of capital investments: drilling wells (calculation of penetration depth depending on the type of well), tacking (number of bushes and 
machines used simultaneously), arrangement of infrastructure (necessary and available capacities);

- operating costs: development time, production and injection levels.

Accounting of capital investments in the development project along with unit hydrocarbon production at the well placement stage allows us to evaluate the feasibility of drilling exact wells.

The main criteria for choosing a forecast well placement system can be divided into several groups. The selection criteria for the well placement system (in-line, three-point, five-point, nine-point, selective) are usually determined by the existing experience in developing this type of reservoir and the proven placement system is used. Different well placement systems are characterized by a different ratio of production and injection wells (which is important for maintaining reservoir pressure), some of the systems have the possibility of transformability (one system can be transformed into another by changing the type of some of the wells or by drilling extra ones). To select the optimal distance between the wells in the system, several variants are calculated [6].

The main criteria for selecting locations for new production wells include:

- distance from the oil-water contact (conditional surface separating oil and water in the oil reservoir and determining the ratio of water and oil in the fluid produced by wells at the field);

- effective oil-saturated thickness (reservoir power determines the volume of hydrocarbons in the reservoir and as a consequence well production rate).

It should be considered that the grid of wells should be regular and correspond to one of the existing systems of well arrangements. However, in some cases it is necessary to use selective well placement systems (high density of existing wells, non-standard form of the reservoir or its small area).

The choice of the type of well (directional, horizontal or sidetrack) is based on the geological and geophysical conditions of the formation. For example, with high ruggedness it is not practical to drill horizontal wells, but the coverage of such wells is higher than directional wells which makes it possible to obtain a higher oil production rate during well operation and, therefore, to reduce the cost of extracting each ton of liquid, also horizontal wells increase the density of the well grid.

To form an effective development management strategy for predictive modeling, development options are configured in accordance with the criteria, some of which are regulated (mandatory) on the state level [6, 7], the others are set by the subsoil user or dictated by the operating conditions of the field, as well as its parameters. For example, it must be considered that many fields are characterized by severe climatic conditions, which imposes a number of restrictions on the intensity of drilling of new wells due to the seasonality of work. The variant recommended for approval must meet the requirements of regulatory documents (established by the government): achieving an approved oil recovery factor (the proportion of hydrocarbon reserves that are technically possible to extract), water cut of $98 \%$ (the percentage of water content in the produced fluid to shutdown both individual production wells and the entire field), minimum well production, production compensation, etc. This variant may not have economic profitability, which is disadvantageous for the subsoil user. Also, restrictions are imposed by the models themselves or the simulators used.

It is proposed to supplement the algorithm for predictive modeling of field development with a new unit for performing a rapid economic assessment $S_{5}^{\prime}$ of the results of calculation iteration (see Fig. 5). Thus, advanced production forecast stage $S_{4}^{\prime}$ can be represented as:

$$
S_{4}^{\prime}=S_{4} \cup S_{5}^{\prime},
$$

where

$$
S_{5}^{\prime} \subset S_{5}
$$

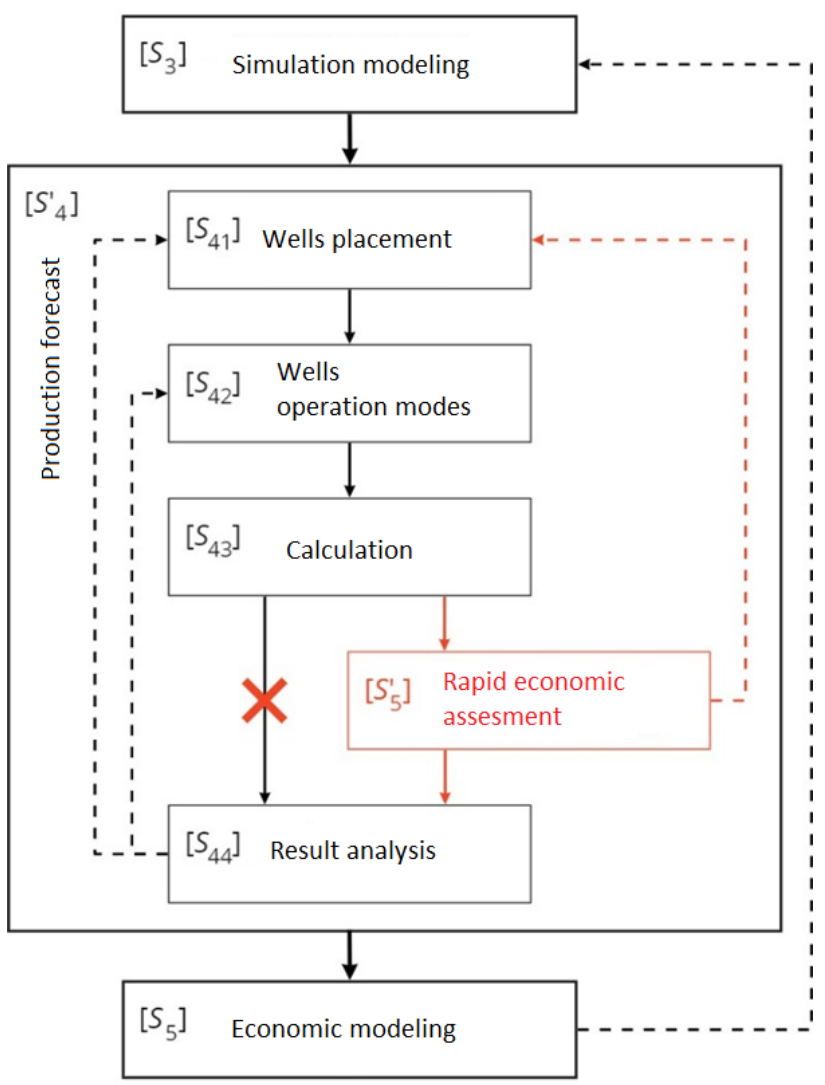

Fig. 5. Advanced algorithm for predictive modeling of field development

At the same time, adding an additional block to the algorithm does not significantly affect the iteration execution time, but it allows significantly reduce the total number of iterations when setting up the $S_{4}$ development forecast by introducing additional restrictions on the placement of forecast production wells: setting boundary conditions by involving the economic component of the project.

The proposed algorithm uses GDM-Tool software (certificate of state registration of a computer program № 2011616248 «GDM-Tool») for well placement $S_{41}$ (depending on the location of the oil-water contact contour and the distribution of oil-saturated thicknesses), setting drilling and operating schedules, as well as operating modes $S_{42}$ of project wells. 
The first iteration of product forecast calculation allows you to get estimated indicators of production levels (starting production and cumulative production of each well) and calculate estimated economic indicators. Based on the obtained data, the forecasted fund of production wells is optimized by eliminating inefficient or obviously unprofitable ones, thereby reducing the number of iterations when setting up a development variant further.

Software Economics (certificate of state registration of a computer program № 2019611730 «Economic rapid assessment of the results of predictive modeling of the development of oil and gas fields (Economics)») is used to perform rapid economic assessment $S_{5}^{\prime}$. It allows you to calculate the main economic indicators of development, as well as to calculate the minimum cost-effective production rate of forecast wells and the minimum cost-effective effective oil-saturated thickness for placing wells for a given field. Thus, it becomes possible to perform adjustment of the prediction well arrangement to reduce the interactiveness of the predictive modeling process.

\section{Results}

To assess the effectiveness of the proposed integrated approach, data on 9 field development projects in the
Tomsk region, completed in different years, was used. The deposits are distinguished by the complexity of their geological structure, different depths of occurrence of productive strata, properties of fluids, degree of exploration and development. Each dataset includes both the complete initial datasets for building models and forecasting development, as well as geological and simulation models and forecasts that have passed government expertise and have been approved as field development strategies.

The forecast variants for hydrocarbon field development were tuned until acceptable indicators were achieved according to the existing algorithm and according to the improved algorithm with the new block of rapid economic assessment. Evaluation of the effectiveness of the proposed approach was carried out by counting the number of iterations of the calculation of one forecast variant for development strategy of hydrocarbon field.

The results are shown in Table 1. For various sets of test data (field development projects), the average number of iterations for setting up production forecast variants for field development was reduced by $15.8 \%$ to $35.6 \%$.

Table 1. Average number of iterations for setting the forecast for field development

\begin{tabular}{|c|c|c|c|}
\hline \multirow[b]{2}{*}{ Data set } & \multicolumn{2}{|c|}{ The average number of iterations, pcs. } & \multirow[b]{2}{*}{ The effect, $\%$} \\
\hline & $\begin{array}{c}\text { Existing project } \\
\text { management algorithm }\end{array}$ & $\begin{array}{c}\text { Advanced project management } \\
\text { algorithm }\end{array}$ & \\
\hline 1 & 7,1 & 4,8 & 32,4 \\
\hline 2 & 7,8 & 6,0 & 23,1 \\
\hline 3 & 6,3 & 4,8 & 23,8 \\
\hline 4 & 5,7 & 4,8 & 15,8 \\
\hline 5 & 10,2 & 7,2 & 29,4 \\
\hline 6 & 9,5 & 7,2 & 24,2 \\
\hline 7 & 5,8 & 4,8 & 17,2 \\
\hline 8 & 9,3 & 7,2 & 22,6 \\
\hline 9 & 14,9 & 9,6 & 35,6 \\
\hline
\end{tabular}

Due to the use of the advanced algorithm with rapid economic assessment, the average number of iterations to configurate one forecast variant was reduced by $25 \%$ (see Fig. 6), which allows us to quickly and with less labor to obtain a design solution for developing a field.

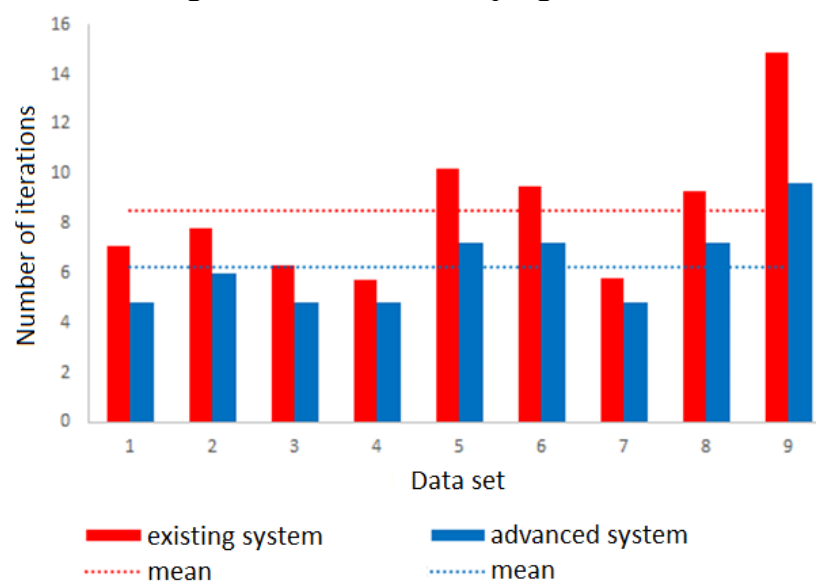

Fig. 6. The number of iterations to configure one forecast variant

\section{Conclusion}

Thus, the use of the rapid economic assessment of hydrocarbon field development forecast variants based on an integrated approach made it possible to advance the existing forecast modeling algorithm and reduce the number of iterations for adjusting the development forecast variant by an average of $25 \%$.

In addition, taking into account the large number of field development forecast variants (which, as in the above example, can reach several tens) considered in the designing process in absolute terms, the reduction in decision-making time in field management is significant.

Moreover, the application of this approach has made it possible to significantly reduce the total volume of capital investments (most of which are precisely the costs of drilling new wells of different types) in field development projects by optimizing the design well stock and thus to improve the economic characteristics of the whole hydrocarbon field development project. 


\section{Acknowledgments}

The reported study was funded by RFBR, project number 18-41-700001.

\section{References}

[1] Skorobogatov, V.A. Research and Development of the Hydrocarbons Potential of the Soils of the Western Siberian Sedimentary Megabasin: Results and Perspectives // Vesti Gazov. Nauk. Mosc.: Gazprom VNIIGAZ LLC. - 2014 (3). - P. 8-26.

[2] Pakyuz-Charrier E., Giraud J., Ogarko V., Lindsay M., Jessell M. Drillhole uncertainty propagation for three-dimensional geological modeling using Monte Carlo // Tectonophysics. - 2018. - №747-748. - P. 16-39.

[3] Neftegazovaya otrasl Rossii. Available online: http://fb.ru/article/263751/neftegazovaya-otraslrossii (accessed on 17 July 2020).

[4] Zavyalov D.A. Improving the accuracy of hydrocarbon reserves estimation based on an integrated approach // CEUR Workshop Proceedings of the $29^{\text {th }}$ International Conference on Computer Graphics and Vision (GraphiCon 2019). - Vol. 2485. - P. 164-167. DOI: 10.30987/graphicon-2019-2-164167.

[5] Yang Y., Zhang M., Bie A., Cui Z., Xia Z. An integrated approach to uncertainty assessment for coalbed methane model // Springer Series in Geomechanics and Geoengineering. - 2019. - P. 1560-1567.

[6] Ministry of Natural Resources of Russia. Guidelines for the preparation of technical projects for the development of hydrocarbon deposits. Available online: http://www.gkz$\mathrm{rf.ru/sites/default/files/docs/metodicheskie} \mathrm{rekomen}$ dacii_po_pravilam_prektirovaniya_uvs.pdf (accessed on 17 July 2020).

[7] Ministry of Natural Resources of Russia. Guidelines for the application of the classification of reserves and resources of oil and combustible gases. Available online: http://www.gkz-

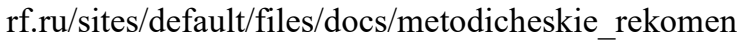
dacii_po_primeneniyu_nkz_utverzhdennye.pdf (accessed on 17 July 2020).

\section{About the authors}

Zavyalov Dmitry A., Tomsk Polytechnic University (Tomsk), Keldysh Institute of Applied Mathematics RAS (Moscow). E-mail: zda@tpu.ru. 